\title{
Parental Supports for Parents With Intellectual and Developmental Disabilities
}

\author{
Elizabeth Lightfoot and Traci LaLiberte
}

The concept of supports is crucial in the lives of all people, especially for those with intellectual and developmental disabilities. In fact, the introduction of the idea of individuals with intellectual and developmental disabilities as needing supports was a crucial step for the American Association on Intellectual and Developmental Disabilities (AAIDD), because this concept is different from the medical model of disability, which is focused on individuals' deficiencies. In the 11th edition of the AAIDD manual, Schalock et al. (2010) defined supports as "resources and strategies that aim to promote the development, education, interests, and personal well-being of a person and that enhance individual functioning" (p. 105). Supports are seen as important for these individuals participating in a variety of life domains, including social roles, which are defined as "valid activities considered normative for a specific age group" (Shalock et al., 2010, p. 16).

Supports for one important social role, however, that is normative for many working-age adults, the social role of parenting, has received little attention in the field. There are currently few formal sources of support to assist parents with intellectual and developmental disabilities in the role of parenting, and many parents with intellectual and developmental disabilities have to rely on informal supports and are at high risk for losing their children.

Over the past several decades, there have been several calls for attention to the need for parental supports, notably by Booth and Booth (1996) from Great Britain and Llewellyn and McConnell (2002) from Australia, and a few innovative programs striving to support individuals with intellectual and developmental disabilities in parenting (Feldman, 2010; Garbus \& Kennedy, 1999; Llewellyn, McConnell, Russo, Mayes, \& Honey, 2002; Feldman, Ducharme, \& Case, 1999). Parents with disabilities have indicated that supports help them to better parent their children (McGaw, Ball \& Clark, 2002; Tarleton \& Ward, 2007). However, programs serving parents with disabilities are scarce, and of these few, many are focused on increasing individual parenting ability, with less emphasis on increasing formal and informal supports.

The notion of parental supports for parents with disabilities in the United States has become more prominent only recently, and a number of new state laws are now mandating courts to look at parental supports for parents with disabilities who are involved in the child welfare system. The child welfare system historically has not recognized the concept of supports for parents with disabilities or the notion of interdependent parenting, although in the past decade, there are a few small, but dramatic changes within the child welfare system signaling that the concept of parental supports may be on the rise. In the present article we discuss the rise of the concept of 


\section{Perspective: Parental supports $\quad$ E. Lightfoot and T. LaLiberte}

parental supports within child welfare legislation, define parental supports for parents with disabilities, and discuss the need for a normalization of the concept of parental supports in the field of intellectual and developmental disabilities.

\section{Parents with Disabilities and Child Protection Laws}

Parents with disabilities in general, and particularly parents with intellectual and developmental disabilities or mental illness, were historically seen as not fit to parent. In the 20th century United States, people with intellectual and developmental disabilities often were forcibly sterilized, or if they had a baby, the baby was removed at birth. With the end of the routine practice of forced sterilization and the rise of self-determination and community living, many adults with intellectual and developmental disabilities are now becoming parents. Although there is some evidence of an increased risk of abuse or neglect if a parent has an intellectual or developmental disability (James, 2004), there is little evidence supporting the assertion that parents with disabilities are considerably more likely to abuse or neglect their children than are parents without disabilities or that most children of parents with intellectual and developmental disabilities have poor outcomes. Nonetheless, parents with disabilities still face substantially increased scrutiny when they encounter the child welfare system in many countries (Llewellyn, McConnell, \& Ferronato, 2003; Lightfoot, Hill, \& LaLiberte, 2010).

The concept of parental supports for parents with disabilities is certainly not present in the majority of child protection laws in the United States. Currently, about three quarters of states include language related to "parental disability" within their state statutes regarding child welfare and termination of parental rights (Lightfoot et al., 2010). Although no state law suggests that a parent's disability alone should be grounds for termination of parental rights, many states direct courts to consider how a parent's intellectual or developmental disability, mental illness, emotional illness, or physical disability affects their ability to parent. Until recently, there was no accompanying direction for courts in any state to consider how parents with disabilities are able to use parental supports to assist them in parenting or to determine parental support needs for parents with disabilities in the development of child protection plans.

A significant concern about the inclusion of disability in the grounds for termination of parental rights is that the mention of parental disability can shift the focus from a parent's behavior to a parent's condition or diagnosis (Lightfoot et al., 2010). There are currently no other parental conditions that are listed in state statutes. In fact, it is explicitly laid out in most state statutes that the condition of parental poverty shall not in and of itself be considered a ground for termination of parental rights. When a parent's disability is explicitly included in legislation outlining the grounds for termination of parental rights, the disability can easily become the focus of a child protection case, even though the statutes do not say it can be the sole grounds for termination. It is much easier to diagnosis a parent's disability, which is often done by a professional in 


\section{Perspective: Parental supports $\quad$ E. Lightfoot and T. LaLiberte}

an office, than it is to assess a person's ability to parent, which would require evaluation of numerous parent-child interactions in natural settings and would arguably also require an assessment of parental supports. There has been a lack of awareness by courts that successful parenting by individuals with disabilities can take place with parental supports. Certainly not all such people parent adequately, even with proper parental supports, just as all parents without disabilities do not parent adequately; however, parenting behavior can only be appropriately evaluated through a comprehensive assessment that includes attention to parental supports.

Over the last decade, several states have changed their child welfare statues to include language requiring courts to take into account the support needs that individual parents can use to successfully parent. Idaho was the first state to include affirmative language in its state child welfare statutes, resulting from a multi-year advocacy campaign culminating in the passage of new laws in 2002 and 2003. Idaho's law now mandates that reasonable efforts to prevent foster care placement or termination of parental rights involving a parent or guardian with a disability shall include, "the consideration of adaptive equipment or support services that may enable the parent to remedy the reasons for removal of the child" (Idaho State Code, 16-2005-6). The statute goes on to define adaptive equipment as "any piece of equipment or any item that is used to increase, maintain or improve the parenting capabilities of a parent with a disability" (Idaho State Code, 16-2002-18) and supportive services as:

Services which assist parents with a disability to compensate for those aspects of their disability which affect their ability to care for their child and which will enable them to discharge their parental responsibilities. The term includes specialized or adapted training, evaluations or assistance with effectively using adaptive equipment and accommodations which allow parents with a disability to benefit from other services including, but not limited to, Braille texts or sign language interpreters (Idaho State Code 16-2002-19).

Vermont, which more recently changed its state law, includes language mandating that in child welfare, there should be:

an appropriate balance between protecting children and respecting the rights of a parent or guardian, including a parent or guardian with disabilities, and shall recognize that persons with a disability can be successful parents. The rules shall include the possible use of adaptive equipment and supports (Vermont State Code 52 § 4922(b)).

The Vermont state statute also requires that the strengths and needs of parents with disabilities are considered within child welfare proceedings.

There has also been a call for further changing legislation to include a focus on parental supports, with the distribution of a widely circulated guide (Lightfoot, LaLiberte 


\section{Perspective: Parental supports $\quad$ E. Lightfoot and T. LaLiberte}

\& Hill, 2007). In addition, advocates within the mental health community have drawn directly upon the language within this guide in their call for changing legislation related to parents with mental health needs (Scott, 2008). With this new attention, there is a need for a clear definition of parental supports for parents with disabilities.

\section{Defining Parental Supports}

Parental supports are akin to parental accommodations that individuals with disabilities need to successfully parent their children, including strategies and techniques designed to support the parent or guardian with a disability in taking care of his or her children. The notion of parental supports as suitable for parenting represents a change in paradigm in the field of child welfare, which typically has viewed independent parenting as crucial. Parents have often been assessed based on whether they can independently be responsible for all aspects of caring for their child or children, even though most parents rely on various formal and informal supports for caregiving. Formal supports that are typically used among North American parents include paid daycare, housecleaning, paid tutoring, or even take-out restaurants. Typical informal supports include grandparents providing a night out for parents (respite care), neighbors shoveling snow off the driveway of a new parent (chore services), or parents joining together for carpooling to soccer practice (transportation services). Supports with parents who have disabilities are similar.

Parental supports for parenting activities for persons with intellectual and developmental disabilities can be defined similarly to the general notion of supports developed by AAIDD. As supports in general for this population are thought to be technologies or personal supports that enhance individual functioning (Schalock et al., 2010), parental supports are simply technologies or personal supports that enhance family functioning in families headed by a parent or guardian with a disability. Technology can include any adaptive equipment that that may assist an individual in parenting, such as adaptive cribs or child care equipment, cooking/feeding equipment, or a smart phone or a Personal Digital Assistant (PDA) that presents step-by-step guidelines for parenting activities.

Personal supports include any support designed to assist parents or guardians with a disability to compensate for those aspects of their disability that affect their ability to care for their child or children and will enable them to fulfill their parenting responsibilities. These types of personal supports could include day care services, respite care, a co-parent or parent mentor, in-home parenting training, money management assistance, homework tutoring, housekeeping, safety planning, or even long-term family foster care. Similar to the general notion that supports help individuals with disabilities fill the gaps between their own competencies and environmental demands (Schalock et al., 2010), parental supports are designed to help individuals with 


\section{Perspective: Parental supports $\quad$ E. Lightfoot and T. LaLiberte}

disabilities fill their gaps in parenting competencies and environmental demands related to parenting.

A key difference from the general notion of supports and parental supports is the focus on the individual versus the family. Although the definition of supports currently used in the AAIDD manual (Schalock et al., 2010) is focused on individual functioning, the notion of parental supports broadens this focus to include an emphasis on family functioning, including the children of parents with disabilities. It makes little sense to evaluate or assess individual functioning or to develop supports for individual functioning when a person with a disability is a parent, because the parent-child relationship is a paramount part of a parent's life. This change in philosophy about parents that is currently reflected in some new state laws influencing child welfare proceedings for parents with disabilities will have great impact on parents with disabilities.

\section{Conclusion}

Some states in the United States are now requiring child welfare agencies and the court system to consider the parental supports of parents with disabilities who become involved in the child welfare system. This is a great step forward for parents with disabilities because there is some evidence that parental supports do help parents take care of their children. The notion of parental supports fits well within the general conception of supports promoted by AAIDD (Shalock et al.). Unfortunately, there are currently few formal programs supporting parents with disabilities and little funding sources to pay for formal or informal parental supports. Nonetheless, these new state statutes represent a shift in our thinking about parental supports for parents with disabilities, and innovative programs supporting parents with disabilities may emerge as child welfare agencies are increasingly required to examine how parents with disabilities can parent their children with the assistance of parental supports. 
Perspective: Parental supports $\quad$ E. Lightfoot and T. LaLiberte

\section{References}

Booth, W., \& Booth, T. (1996). Supported parenting for people with learning difficulties: Lessons from Wisconsin. Representing Children, 9, 99-107.

Feldman, M. A. (2010). Parenting education programs. In G. Llewellyn, R. Traustadóttir, D. McConnell, \& H. Sigurjónsdóttir (Eds.), Parents with intellectual disabilities: Past, present futures (pp. 121-136). West Sussex, UK: Wiley-Blackwell.

Feldman, M. A., Ducharme, J. M., \& Case, L. (1999). Using self-instructional pictorial manuals to teach child-care skills to mothers with intellectual disabilities. Behavior Modification, 23, 480-497.

Garbus, L., \& Kennedy, R. (Producers/Directors). (1999). Different moms [motion picture]. United States: Moxie Firecracker Films.

James, H. (2004). Promoting effective work with parents with learning disabilities. Child Abuse Review, 13, 31-41.

Lightfoot, E., Hill, K., \& LaLiberte, T. (2010). Disability in the termination of parental rights and other child custody statutes. Child Abuse and Neglect, 34, 927-934. doi:10.1016/j.chiabu.2010.07.001

Lightfoot, E., LaLiberte, T., \& Hill, K. (2007). Guide to creating legislative change: Disability status in termination of parental rights and other child custody statutes. Minneapolis: University of Minnesota. Retrieved from http://www.cehd.umn.edu/ssw/CASCW/attributes/PDF/LegislativeChange.pdf

Llewellyn, G., \& McConnell, D. (2002). Mothers with learning difficulties and their support networks. Journal of Intellectual Disability Research, 46, 17-34.

Llewellyn, G., McConnell, D., \& Ferronato, L. (2003). Prevalence and outcomes for parents with disabilities and their children in an Australian court sample. Child Abuse and Neglect, 27, 235-251.

Llewellyn, G., McConnell, D., Russo, D., Mayes, R., \& Honey, A. (2002). Home based programs for parents with learning difficulties: Lessons from practice. Journal of Applied Research in Intellectual Disabilities, 15, 341-353.

McGaw, S., Ball, K., \& Clark, A. (2002). The effect of group interventions on the relationships of parents with intellectual disabilities. Journal of Applied Research in Intellectual Disabilities, 15, 354-366.

Scott, J. (2008). Supporting parents with psychiatric disabilities: A model reunification statute. Philadelphia: University of Pennsylvania, Collaboration on Community Integration. Retrieved from http://tucollaborative.org/pdfs/Toolkits_Monographs_Guidebooks/parenting/A_Mo del_Reunification_Statute.pdf

Schalock, R. L., Borthwick-Duffy, S. A., Bradley, V. J., Buntinx, W. H. E., Coulter, D. L., Craig, E. M., et al. (2011). Intellectual disability: Definition, classification, and systems of supports (11th ed.). Washington, DC: American Association on Intellectual and Developmental Disabilities. 
Perspective: Parental supports $\quad$ E. Lightfoot and T. LaLiberte

Tarleton, B., \& Ward, L. (2007). "Parenting with "support": The views and experiences of parents with intellectual disabilities. Journal of Policy and Practice in Intellectual Disabilities, 3, 194-202.

\section{Authors:}

Elizabeth Lightfoot, PhD (e-mail: elightfo@umn.edu), Associate Professor, School of Social Work; and Traci LaLiberte, PhD, Director, Center for Advanced Studies in Child Welfare, School of Social Work, University of Minnesota, 205 Peters Hall, 1404 Gortner Ave., Saint Paul, MN 55108. 